\title{
BMJ Open Occupational exposure to silica and risk of heart disease: a systematic review with meta-analysis
}

\author{
Kai Liu (D) , ${ }^{1}$ Min Mu, ${ }^{2}$ Kehong Fang, ${ }^{3}$ Yuanyuan Qian, ${ }^{1}$ Song Xue, ${ }^{4}$ Weijiang Hu, ${ }^{5}$ \\ Meng $\mathrm{Ye}^{1}$
}

To cite: Liu K, Mu M, Fang K, et al. Occupational exposure to silica and risk of heart disease: a systematic review with meta-analysis. BMJ Open 2020;10:e029653. doi:10.1136/ bmjopen-2019-029653

- Prepublication history and additional material for this paper are available online. To view these files, please visit the journal online (http://dx.doi. org/10.1136/bmjopen-2019029653).

Received 07 February 2019 Revised 14 November 2019 Accepted 22 November 2019

Check for updates

(C) Author(s) (or their employer(s)) 2020. Re-use permitted under CC BY-NC. No commercial re-use. See rights and permissions. Published by BMJ.

For numbered affiliations see end of article.

Correspondence to

Mr Meng Ye;

yemeng@niohp.chinacdc.cn

\section{ABSTRACT}

Objective To search for evidence of the relationship between occupational silica exposure and heart disease. Design A systematic review and meta-analysis. Background Growing evidence suggests a relationship between occupational silica exposure and heart disease; however, the link between them is less clear.

Data sources PubMed, ScienceDirect, Springer and EMBASE were searched for articles published between 1 January 1995 and 20 June 2019. Articles that investigated the effects of occupational silica exposure on the risk of heart disease were considered.

Study selection We included cohort studies, including prospective, retrospective and retroprospective studies. Data extraction and synthesis We extracted data using a piloted data collection form and conducted randomeffects meta-analysis and exposure-response analysis. The meta-relative risk (meta-RR), a measure of the average ratio of heart disease rates in those with and without silica exposure, was used as an inverse varianceweighted average of relative risks from the individual studies. The Newcastle-Ottawa Quality Assessment Scale for cohort studies was used for study quality assessment. Outcome measure We calculated the risk of heart diseases such as pulmonary heart disease, ischaemic heart disease and others.

Results Twenty cohort studies were included. The results suggest a significant increase in the risk of overall heart disease (meta-RR=1.08, $95 \% \mathrm{Cl} 1.03$ to 1.13 ). Stronger evidence of association with pulmonary heart disease was found in the risk estimate of both categories of heart disease (meta- $\mathrm{RR}=1.24,95 \% \mathrm{Cl} 1.08$ to 1.43 ) and in the exposure-response analysis (meta- $\mathrm{RR}=1.39,95 \% \mathrm{Cl} 1.19$ to 1.62). Our subgroup analyses also revealed that the statistical heterogeneity among studies could be attributed mainly to the diversity in reference group, occupation and study quality score.

Conclusions Silica-exposed workers are at an increased risk for overall heart disease, especially pulmonary heart disease. Further research is needed to better clarify the relationship between occupational silica exposure and ischaemic heart disease.

PROSPERO registration number CRD42019124673.

\section{INTRODUCTION}

Silica is the key ingredient of dust, with widespread human exposure in a working

\section{Strengths and limitations of this study}

- We used comprehensive and robust search strategy, including a broad literature search and a piloted data collection.

- Sensitivity analysis was conducted to examine the influence of specific studies on overall heart disease.

- Subgroup analyses and exposure-response analyses were also performed.

- A major limitation was the high heterogeneity among studies, precluding to some degree firm conclusions.

- There were few articles included in the exposureresponse analyses.

environment. Occupational silica exposure has long been recognised as a threat to workers' health, causing diseases that include autoimmune diseases, silicosis, tuberculosis, lung cancer and other non-malignant respiratory diseases. ${ }^{1-10}$ Although the International Agency for Research on Cancer has classified respirable crystalline silica as a human carcinogen in 1997, there are still a large number of workers exposed to silica. ${ }^{11} 12$ The US Occupational Safety and Health Administration estimated that there were about 2.2 million American workers exposed to silica in $2016 .^{12}$

There has been increasing recognition that occupational silica exposure may be responsible for heart diseases, with several epidemiological studies showing that cardiovascular disease (CVD) mortality is significantly higher in silica-exposed workers, although at different concentrations. ${ }^{13-21}$ Nevertheless, the link between silica exposure and risk of heart disease mortality or morbidity is still controversial, especially ischaemic heart disease. Fan et $a l^{13}$ revealed that Swedish foundry workers exposed to respirable silica did not exhibit elevated morbidity and mortality from myocardial infarction. However, some earlier research came to opposite conclusions. ${ }^{1422-27}$ 
In 1997, Sjogren ${ }^{28}$ published a review article on ischaemic heart disease among quartz-exposed workers. The author concludes that stonecutters, carvers and African gold miners are at a high risk for myocardial infarction or ischaemic heart disease, but this could not be explained by differences in smoking habits or different sample sizes. ${ }^{28}$ On this background, we conducted a systematic literature review and meta-analysis of occupational silica exposure and heart disease.

\section{METHODS}

We performed a systematic review and meta-analysis according to the guidelines of the Preferred Reporting Items for Systematic Reviews and Meta-Analyses. ${ }^{29}$ The objective was formulated using the PICOS criteria (PICOS: population: workers; intervention: exposure to silica or quartz; comparison: non-exposed silica workers or general population; outcome: heart disease; study: cohort studies).

\section{Type of studies}

We included cohort studies, including prospective, retrospective and retroprospective studies.

\section{Search strategy}

We carried out literature search in PubMed, ScienceDirect, Springer and EMBASE without language restrictions (from 1 January 1995 to 22 December 2018) using free text and keywords. The original literature search was updated on 20 June 2019. Search terms for occupational silica exposure included 'silica' as well as other related vocabulary (quartz, dust, coal, pottery, mine, sand, granite and stone). Online supplementary file 1 provides the full search strategy for PubMed, which was adapted and used to search other databases. For completeness, we also searched all references cited in the original papers and authors' other related studies.

\section{Study population and exposure definition}

The exposure of interest was silica dust, and we included studies with silica-exposed workers. In addition to the ever/never exposed inclusion criteria, some other additional characteristics of workers were included in our analyses: exposure measurement method (including cumulative exposure, qualitative exposure or mean exposure), exposure assessment method (including sample monitoring, job exposure matrix or approximation), exposure type (including silica dust with asbestos, silica dust without asbestos, silica mixed dust and silica dust with trichloroethylene), silica particle size (including respirable silica and other particle sizes) and exposure level $\left(\mathrm{mg} / \mathrm{m}^{3}\right.$-years $)$.

\section{Outcome definition}

The main outcome was heart disease fulfilling the International Classification of Diseases 6, 7, 8, 9 and 10 criteria. Categories of heart disease mainly included pulmonary heart disease, ischaemic heart disease and other heart diseases. Ischaemic heart disease included myocardial infarction and coronary heart disease. Other heart diseases included hypertensive heart disease and chronic rheumatic heart disease. Furthermore, there were six articles that reported only the risk of 'all heart disease', so we classified 'all heart disease' as the fourth category, including CVD. Standardised mortality ratio for underlying ischaemic heart disease was included in our analyses. $^{7}$

\section{Study quality assessment}

The Newcastle-Ottawa Quality Assessment Scale for cohort studies was used for quality assessment and one point for every satisfactory answer. ${ }^{30}$ Eight items were assessed to calculate study quality score: representativeness of the exposed cohort, selection of the non-exposed cohort, ascertainment of exposure, demonstration that outcome of interest was not present at start of study, comparability of cohorts on the basis of design or analysis, assessment of outcome, follow-up long enough for outcomes to occur or not, and adequacy of follow-up (online supplementary file 2).

\section{Study and data collection processes}

Four authors (KL, MY, MM and WH) designed this study. $\mathrm{MY}$ and $\mathrm{WH}$ assessed the full-text articles according to the exclusion and inclusion criteria. Two reviewers (KL and MM) extracted the study characteristics, outcomes and study quality data using a piloted data collection form. Only studies with high methodological quality, that is, with a score of 6 or higher, were included. All reviewers independently reviewed the titles and abstracts of all identified citations. Disagreements were resolved by discussion and consensus, with MM as an adjudicator.

\section{Statistical analysis}

The relative risk or coefficient value is ordinarily not constant across study populations. ${ }^{31}$ Pooled statistics could be a useful summary but generally cannot be an accurate estimate. The SE and confidence limits for the common effect could not adequately reflect the variability and range of accurate effect if important heterogeneity is present. ${ }^{31}$ Thus, we used random-effects model to calculate the meta-relative risk (meta-RR), a measure of the average ratio of heart disease rates in those with and without silica exposure, as an inverse variance-weighted average of relative risks from the individual studies. ${ }^{31}$ We calculated the variance estimate, $I^{2}$, as a measure of heterogeneity among studies. ${ }^{32}$ The weight of the result was computed from the individual original estimate SE as $1 /$ SE. ${ }^{2}$ All statistical analyses were performed using STATA V.15.0 (metan, metabias and funnel commands). ${ }^{33}$

First, we assessed publication bias by conducting Egger's linear regression test. Second, sensitivity analysis was performed to account for bias in study selection. Third, we conducted subgroup analyses stratified by study reference group, occupation, duration of follow-up, adjustment for smoking, year of publication, sample size, 


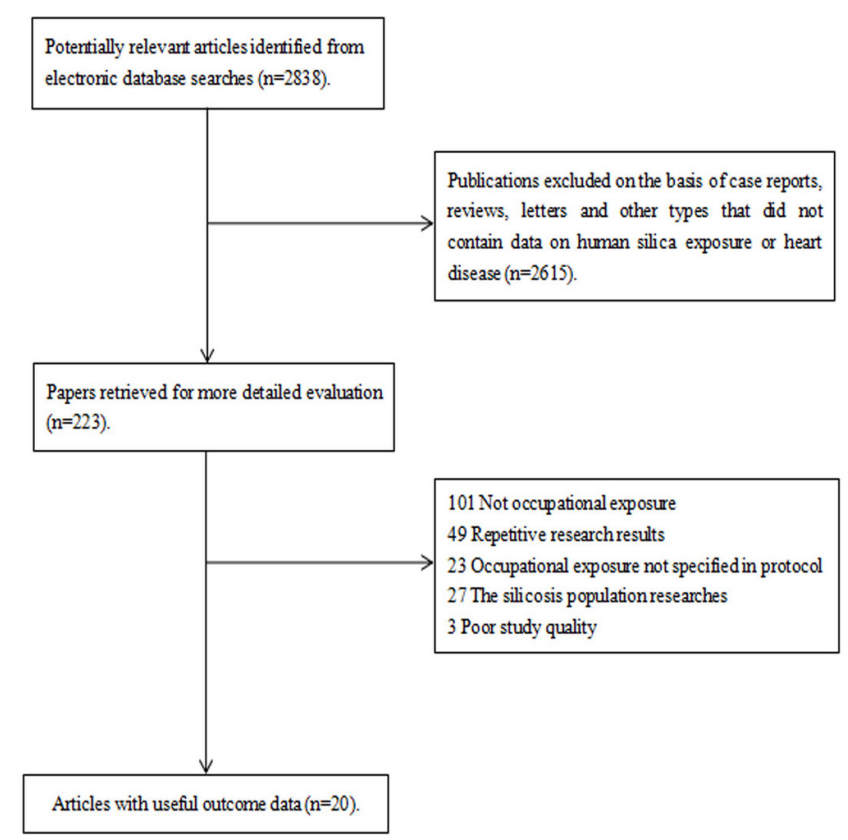

Figure 1 Flow chart of study selection for meta-analysis.

study quality score, race, gender, exposure measurement method, exposure assessment method, exposure type, research category and silica particle size. Fourth, we conducted exposure-response analyses for ischaemic and pulmonary heart disease using penalised spline models. The original cumulative silica exposure data $\left(\mathrm{mg} / \mathrm{m}^{3}\right.$ years) were estimated by linking a job exposure matrix to each person's work history. Moreover, an overall $\mathrm{p}$ value of testparm doses results was calculated to test the linearity in exposure-response analyses: $p$ for linearity trend $>0.05$; $p$ for non-linearity trend $<0.05$. Midpoints of cumulative silica exposure categories were used for doseresponse calculations. If cumulative silica exposure intervals were provided, the midpoint between the lower and upper bounds was regarded as the corresponding cumulative silica exposure dose. For open-ended upper and lower categories, midpoints were calculated separately as the lower boundary multiplied by 1.2 or as the upper boundary divided by $1.2 .^{34}$

\section{Patient involvement}

Patients or the public were not directly involved in the study. We used data from published papers only.

\section{RESULTS}

\section{Overview of studies included in the systematic review}

Study selection is described in figure 1. We identified 2838 articles: 2608 of the original literature search (from 1 January 1995 to 22 December 2018) and 230 new articles from the updated search but none included in the analysis (from 23 December 2018 to 20 June 2019). Case reports, reviews, letters and papers not related to heart disease were excluded. This left 223 articles for full-text review. A total of 203 articles were excluded after fulltext review for the following reasons: (1) 101 were not on occupational exposure to silica; (2) 49 were duplicate publications on the same population; (3) $23 \mathrm{did}$ not provide specific occupational exposure data such as whether low-level dust was equal to occupational silica exposure $>0 \mathrm{mg} / \mathrm{m}^{3}{ }^{35}$; (4) 27 were based on patients with pneumoconiosis; and (5) 3 were of poor quality. The remaining 20 articles reported 28 original heart disease risk estimates and were included in the meta-analysis.

Table 1 and online supplementary file 2 show the characteristics of the included studies. The sample size of studies ranged from 1817 to 74040 . Seven studies were conducted in China, six in the USA, three in Sweden, three in the UK and one in South Africa. Two studies reported the risk of ischaemic heart disease incidence, ${ }^{13} 15$ and 19 reported on the risk of heart disease mortality. ${ }^{7-10} 1314$ 16-27 Categories of heart diseases ranged from ischaemic heart disease and pulmonary heart disease, to other heart diseases. A total of 14 studies provided data on the risk of ischaemic heart disease, including myocardial infarction and coronary heart disease ${ }^{6-1013-23} ; 5$ reported on the risk of pulmonary heart disease ${ }^{79101417}$; and 2 discussed the risk of other heart diseases. ${ }^{1014}$ All 20 studies had quality scores ranging from 6 to 9 , with 9 studies having high quality score of $\geq 8$. ${ }^{61014-182224}$

\section{Overall and categories of heart disease risk estimate}

The relationship between occupational silica exposure and overall heart disease is shown in figure 2. The results suggest a significant increase in overall heart disease risk (meta-RR=1.08, 95\% CI 1.03 to $\left.1.13, I^{2}=96.0 \%, \mathrm{p}<0.05\right)$.

In the risk estimate analysis of heart disease categories (figure 2), ischaemic heart disease presented a slight but non-significant increase (meta-RR=1.07, 95\% CI 1.00 o $1.16, p=0.058)$, while statistically significant positive association was observed for pulmonary heart disease (meta-RR=1.24, 95\% CI 1.08 to $1.43, \mathrm{p}=0.002$ ). Analysis of studies with other heart diseases showed a slight decrease (meta-RR=0.96, 95\% CI 0.94 to $0.99, \mathrm{p}=0.002$ ).

\section{Publication bias}

Egger's linear regression test indicated that there was no publication bias $(\mathrm{p}=0.446,95 \%$ CI -1.308 to 2.890$)$ (figure 3).

\section{Sensitivity analysis}

We deleted one risk estimate from the overall meta-risk estimate each time to check the effect of the removed data. Sensitivity analysis indicated that 12 studies and pulmonary heart disease mortality data from Dong et $a l$ and Lai et al were the main origin of heterogeneity. ${ }^{6} 8-101314162021$ 23-27 The heterogeneity decreased significantly after excluding the risk estimates of the main origin of heterogeneity (before exclusion: $I^{2}=96.0 \%$, $\mathrm{p}=0.000$; after exclusion: $\left.I^{2}=35.3 \%, \mathrm{p}=0.135\right)$, while the positive association between occupational silica exposure and heart disease was not materially changed (meta$\mathrm{RR}=1.14,95 \%$ CI 1.08 to $1.20, \mathrm{p}=0.000)$. 
Table 1 Summary information of cohort studies on silica-exposed workers, published between 1 January 1995 and 20 June 2019

\section{Authors}

and year of Country and study

publication

population

Follow-

Lu et al

$(2012)^{15}$

China, 1817 workers

(1318 male and 499

female) in automobile

Employment

up period,

period outcome

\section{Heart disease}

SMR/(S)RR/HR

1980-1996

1980-2009

Incidence

(ICD codes)

Deaths/cases

$(95 \% \mathrm{Cl})^{*}$

foundry.

Fan et al

Sweden, 2551 male

$(2018)^{13} \quad$ workers in 11 foundries.

1913-2005

1987-2012

Ischaemic heart disease

156

1.46 (1.02 to 2.08$)$

(ICD: unspecified)

Mortality

Incidence

Cardiovascular disease
(ICD-10 codes)

Myocardial infarction

(ICD-10: I21-I22)

\begin{tabular}{lllllrr}
$\begin{array}{l}\text { Vacek et al } \\
(2011)^{8}\end{array}$ & $\begin{array}{l}\text { USA, } 7052 \text { male workers } \\
\text { in granite industry. }\end{array}$ & 1947-1998 & $\begin{array}{l}1947-2004 \\
\text { Mortality }\end{array}$ & $\begin{array}{l}\text { All heart diseases (ICD-9 } \\
\text { codes) }\end{array}$ & 1219 & 0.89 (0.84 to 0.94$)$ \\
$\begin{array}{l}\text { Dong et al } \\
(1995)^{9}\end{array}$ & $\begin{array}{l}\text { China, } 17 \text { 696 male } \\
\text { workers at 11 refractory }\end{array}$ & $\begin{array}{l}\text { Before 1962- } \\
1985\end{array}$ & $\begin{array}{l}1962-1985 \\
\text { Mortality }\end{array}$ & $\begin{array}{l}\text { Pulmonary heart disease } \\
\text { (ICD-7 codes) }\end{array}$ & 92 & $1.79(1.35$ to 2.38) \\
\hline
\end{tabular}
plants and 10 rolling steel mills.

\begin{tabular}{|c|c|c|c|c|c|c|}
\hline $\begin{array}{l}\text { Weiner et al } \\
(2007)^{16}\end{array}$ & $\begin{array}{l}\text { Sweden, } 11896 \text { male } \\
\text { mine and stone workers. }\end{array}$ & 1970-1995 & $\begin{array}{l}1970-1995 \\
\text { Mortality }\end{array}$ & $\begin{array}{l}\text { Ischaemic heart disease } \\
\text { (ICD-8 and ICD-9 codes) }\end{array}$ & 1432 & 1.31 (1.24 to 1.38$)$ \\
\hline $\begin{array}{l}\text { Liu et al } \\
(2014)^{14}\end{array}$ & $\begin{array}{l}\text { China, } 42572 \text { workers } \\
\text { ( } 36168 \text { male and } 6404 \\
\text { female) at } 29 \text { metal } \\
\text { mines and pottery } \\
\text { factories. }\end{array}$ & $1915-1974$ & $\begin{array}{l}1960-2003 \\
\text { Mortality }\end{array}$ & $\begin{array}{l}\text { Pulmonary heart disease } \\
\text { (ICD-10: I00-I09) } \\
\text { Ischaemic heart disease } \\
\text { (ICD-10: I11) } \\
\text { Hvpertensive heart disease }\end{array}$ & $\begin{array}{l}1528 \\
496 \\
322 \\
500\end{array}$ & $\begin{array}{l}1.30(1.26 \text { to } 1.33) \\
0.98(0.94 \text { to } 1.02) \\
0.96(0.92 \text { to } 1.00) \\
0.93(0.89 \text { to } 0.96)\end{array}$ \\
\hline
\end{tabular}
factories.

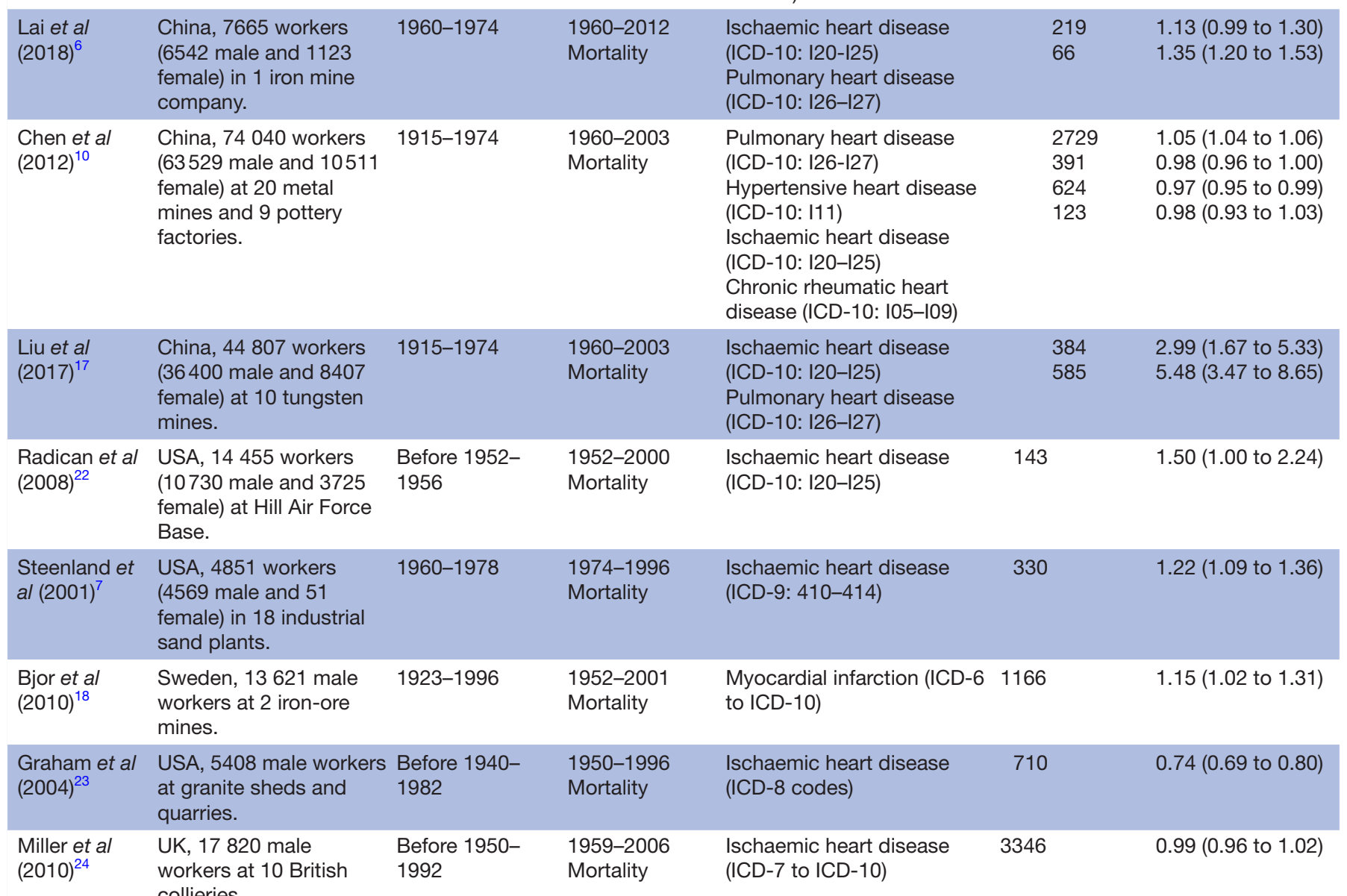




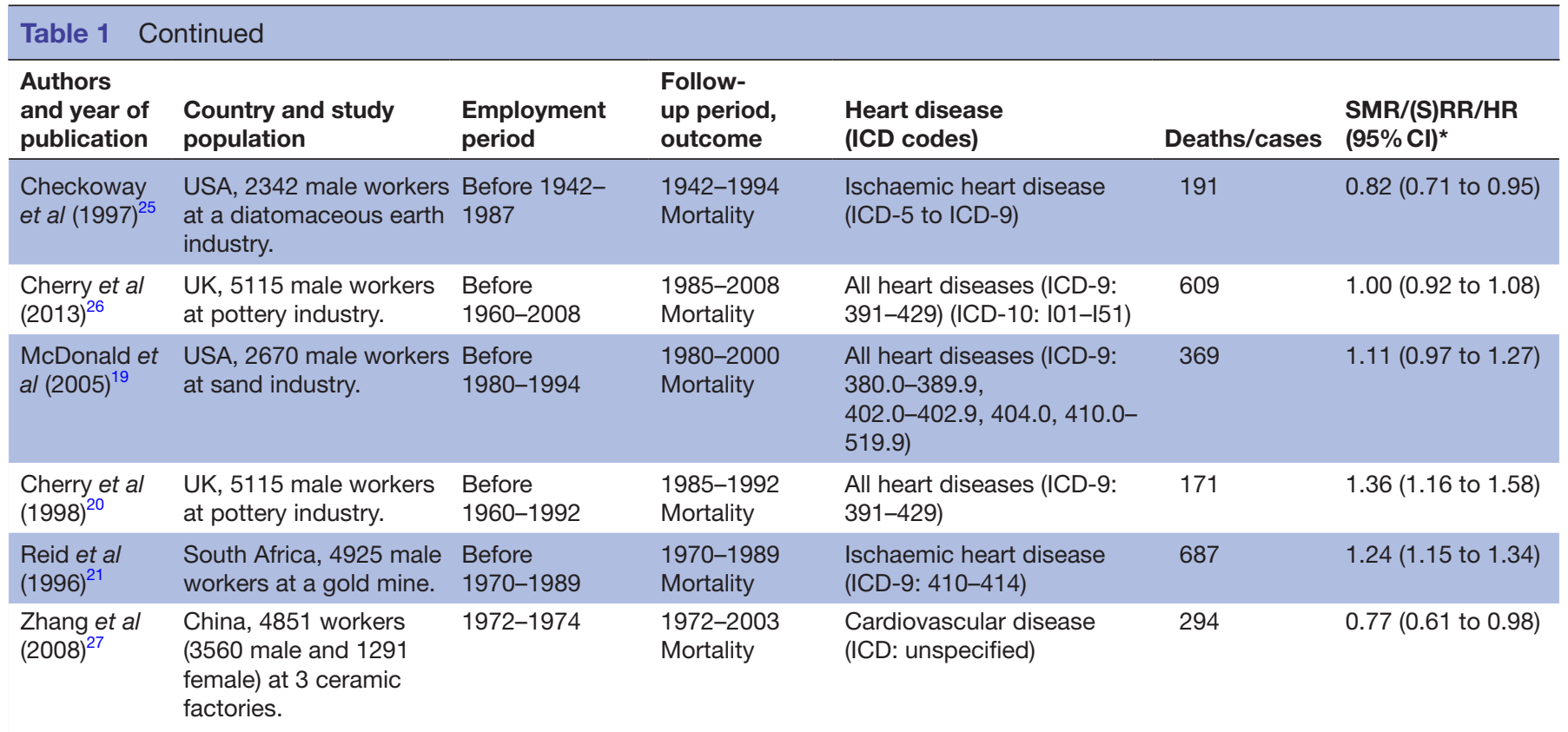

*If a paper provides both SMR and RR values, the RR value is presented.

ICD, International Classification of Diseases; RR, relative risk ; SMR, standardised mortality ratio; SRR, standardised rate ratio.

\section{Subgroup analyses}

We conducted subgroup analyses by study reference group, occupation, duration of follow-up, adjustment for smoking, race, year of publication, sample size, study quality score, gender, exposure measurement method, exposure assessment method, exposure type, research category and silica particle size (table 2).

The results of subgroup analyses revealed significantly increased risk of heart disease, especially in the analysis of studies with external control (meta-RR $=1.53$, 95\% CI 1.19 to $1.95, I^{2}=43.2 \%, \mathrm{p}=0.152$ ), with a study quality score of 6 (meta-RR=1.35, 95\% CI 1.17 to $\left.1.57, I^{2}=69.8 \%, \mathrm{p}=0.019\right)$ and with qualitative exposure measurement method (meta-RR=1.37, 95\% CI 1.06 to $1.76, I^{2}=67.6 \%, \mathrm{p}=0.046$ ). Meanwhile, positive associations were limited, such as in the analysis of studies with 50-58 years of follow-up, with a quality score of 7 and with mean exposure measurement. The statistical heterogeneity among studies could

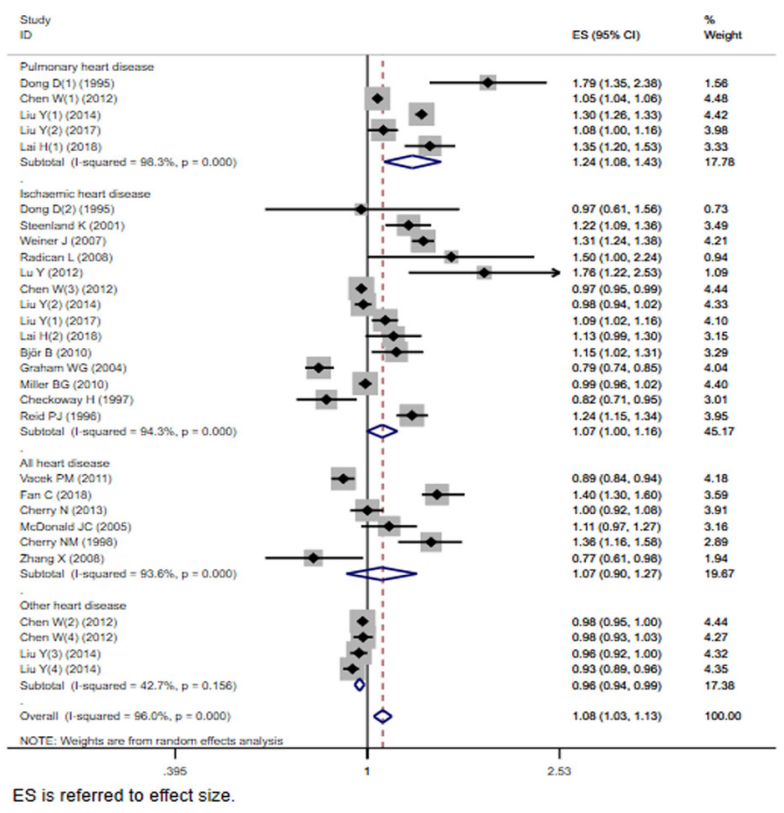

Figure 2 Forest plot of the association between occupational silica exposure and risk of heart disease. ES, effect size.

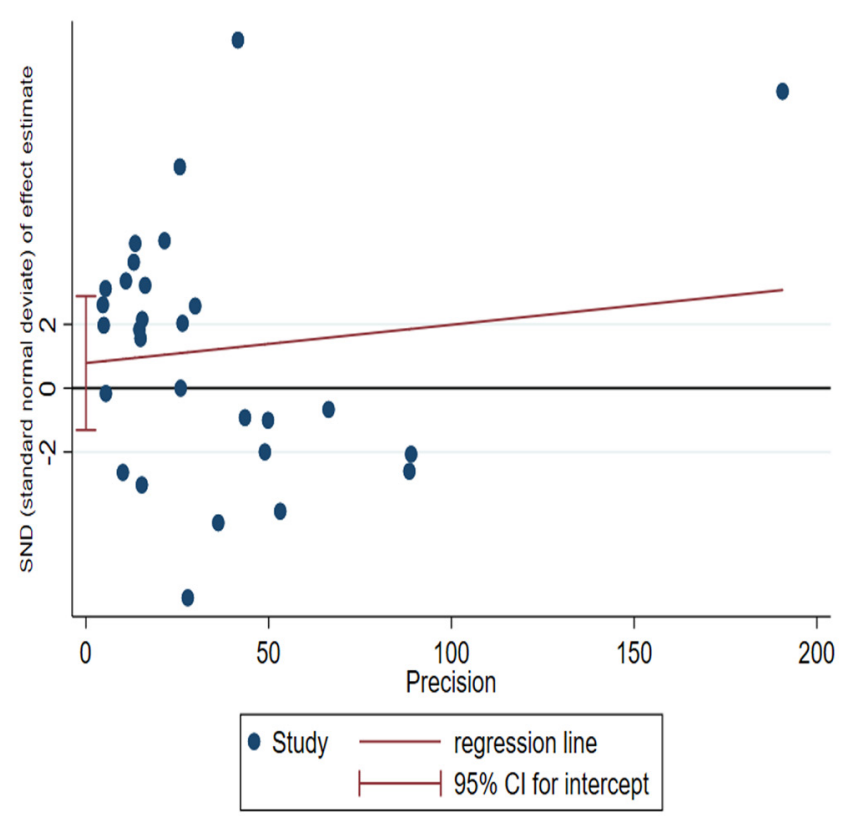

Figure 3 Egger's publication bias plot. 
Table 2 Subgroup analyses of silica exposure and heart disease

\begin{tabular}{|c|c|c|c|c|c|c|}
\hline Study characteristics & Category & $\begin{array}{l}\text { Cohorts } \\
\text { (n) }\end{array}$ & $\begin{array}{l}I^{2} \text { value } \\
(\%)\end{array}$ & $\begin{array}{l}\text { P value for } \\
\text { heterogeneity }\end{array}$ & $\begin{array}{l}\text { Meta-RR } \\
(95 \% \mathrm{Cl})\end{array}$ & $\mathrm{Tau}^{2}$ \\
\hline \multicolumn{7}{|l|}{ Reference group } \\
\hline & Internal control & 7 & 96.8 & 0.000 & 1.04 (0.99 to 1.09$)$ & 0.0079 \\
\hline & External control & 3 & 43.2 & 0.152 & 1.53 (1.19 to 1.95$)$ & 0.0272 \\
\hline & Total population control & 10 & 96.2 & 0.000 & 1.09 (0.95 to 1.25$)$ & 0.0466 \\
\hline \multicolumn{7}{|l|}{ Occupation } \\
\hline & Iron and steel foundry workers & 3 & 75.7 & 0.006 & 1.38 (1.03 to 1.84$)$ & 0.0614 \\
\hline & Mine and stone foundry workers & 15 & 96.6 & 0.000 & $1.04(1.00 \text { to } 1.09)^{*}$ & 0.0104 \\
\hline & Other unspecified workers & 2 & 0.0 & 0.745 & $1.42(1.27$ to 1.58$)$ & 0.0000 \\
\hline \multicolumn{7}{|l|}{ Duration of follow-up } \\
\hline & $8-25$ & 6 & 80.6 & 0.000 & 1.21 (1.08 to 1.36$)$ & 0.0163 \\
\hline & $26-32$ & 4 & 87.2 & 0.000 & 1.24 (1.03 to 1.50$)$ & 0.0306 \\
\hline & $33-49$ & 7 & 97.2 & 0.000 & 1.03 (0.98 to 1.09$)$ & 0.0086 \\
\hline & $50-58$ & 3 & 93.7 & 0.000 & 0.96 (0.77 to 1.22$)$ & 0.0447 \\
\hline \multicolumn{7}{|l|}{ Adjustment for smoking } \\
\hline & Yes & 8 & 96.6 & 0.000 & $1.06(1.01$ to 1.11$)$ & 0.0080 \\
\hline & No & 12 & 95.2 & 0.000 & $1.11(0.97$ to 1.26$)$ & 0.0522 \\
\hline \multicolumn{7}{|l|}{ Race } \\
\hline & Yellow & 7 & 96.6 & 0.000 & 1.06 (1.01 to 1.12$)$ & 0.0090 \\
\hline & White & 13 & 95.4 & 0.000 & 1.01 (0.99 to 1.22$)$ & 0.0306 \\
\hline \multicolumn{7}{|l|}{ Year of publication } \\
\hline & 1995-2001 & 6 & 88.1 & 0.000 & $1.13(0.95$ to 1.34$)$ & 0.0430 \\
\hline & 2002-2008 & 4 & 97.7 & 0.000 & $1.12(0.82$ to 1.54$)$ & 0.0959 \\
\hline & 2009-2015 & 7 & 97.3 & 0.000 & $1.02(0.97$ to 1.07$)$ & 0.0082 \\
\hline & 2016-2018 & 3 & 84.2 & 0.000 & 1.20 (1.08 to 1.33$)$ & 0.0121 \\
\hline \multicolumn{7}{|l|}{ Sample size } \\
\hline & $<10000$ participants & 11 & 94.3 & 0.000 & 1.07 (0.94 to 1.22$)$ & 0.0454 \\
\hline & 10000-20 000 participants & 5 & 94.8 & 0.000 & 1.24 (1.03 to 1.48$)$ & 0.0360 \\
\hline & $>40000$ participants & 4 & 97.5 & 0.000 & 1.04 (0.98 to 1.10$)$ & 0.0084 \\
\hline \multicolumn{7}{|l|}{ Study quality score } \\
\hline & 6 & 3 & 69.8 & 0.019 & 1.35 (1.17 to 1.57$)$ & 0.0132 \\
\hline & 7 & 8 & 91.1 & 0.000 & 1.00 (0.89 to 1.13$)$ & 0.0292 \\
\hline & 8 & 5 & 95.1 & 0.000 & $1.22(1.05$ to 1.43$)$ & 0.0310 \\
\hline & 9 & 4 & 97.7 & 0.000 & $1.03(0.97$ to 1.09$)$ & 0.0083 \\
\hline \multicolumn{7}{|l|}{ Gender } \\
\hline & Only male & 12 & 95.4 & 0.000 & 1.10 (0.99 to 1.22$)$ & 0.0323 \\
\hline & Male and female & 8 & 96.6 & 0.000 & 1.07 (1.01 to 1.12$)$ & 0.0089 \\
\hline \multicolumn{7}{|l|}{$\begin{array}{l}\text { Exposure measurement } \\
\text { method }\end{array}$} \\
\hline & Qualitative exposure measurement & 2 & 67.6 & 0.046 & 1.37 (1.06 to 1.76$)$ & 0.0332 \\
\hline & Cumulative exposure measurement & 17 & 95.7 & 0.000 & 1.07 (1.03 to 1.12$)$ & 0.0092 \\
\hline & Mean exposure measurement & 1 & $\dagger$ & $\dagger$ & 0.79 (0.74 to 0.85$)$ & 0.0000 \\
\hline \multicolumn{7}{|l|}{$\begin{array}{l}\text { Exposure assessment } \\
\text { method }\end{array}$} \\
\hline & Sample monitoring & 8 & 93.1 & 0.000 & $1.07(0.95$ to 1.20$)$ & 0.0265 \\
\hline & Job exposure matrix & 7 & 96.9 & 0.000 & $1.05(1.00$ to 1.11$) \ddagger$ & 0.0089 \\
\hline & Approximation & 5 & 83.3 & 0.000 & 1.27 (1.06 to 1.52$)$ & 0.0281 \\
\hline
\end{tabular}


Table 2 Continued

\begin{tabular}{|c|c|c|c|c|c|c|}
\hline Study characteristics & Category & $\begin{array}{l}\text { Cohorts } \\
\text { (n) }\end{array}$ & $\begin{array}{l}I^{2} \text { value } \\
(\%)\end{array}$ & $\begin{array}{l}P \text { value for } \\
\text { heterogeneity }\end{array}$ & $\begin{array}{l}\text { Meta-RR } \\
(95 \% \mathrm{Cl})\end{array}$ & $\mathrm{Tau}^{2}$ \\
\hline \multicolumn{7}{|l|}{ Exposure type } \\
\hline & Silica mixed dust & 8 & 96.4 & 0.000 & $1.12(0.96$ to 1.30$)$ & 0.0417 \\
\hline & Silica dust without asbestos & 4 & 90.6 & 0.000 & $1.06(0.91$ to 1.24$)$ & 0.0219 \\
\hline & Retrospective cohort study & 4 & 87.8 & 0.000 & $1.04(0.80$ to 1.36$)$ & 0.0753 \\
\hline & Prospective cohort study & 15 & 96.8 & 0.000 & 1.07 (1.02 to 1.12$)$ & 0.0106 \\
\hline & Retroprospective cohort study & 1 & $\dagger$ & $\dagger$ & 1.24 (1.05 to 1.48$)$ & $\dagger$ \\
\hline \multicolumn{7}{|l|}{ Silica particle size } \\
\hline
\end{tabular}

${ }^{*}$ The exact $95 \% \mathrm{Cl}$ range is 0.998 to 1.092 .

†Excluded due to lack of data or only one article giving an estimate.

†The exact $95 \% \mathrm{Cl}$ range is 1.000 to 1.108 .

$\S$ The exact $95 \% \mathrm{Cl}$ range is 1.002 to 2.245 .

$\mathrm{RR}$, relative risk; TCE, trichloroethylene.

be attributed mainly to the diversity in reference group, occupation and study quality score.

\section{Exposure-response analyses}

Our exposure-response analyses were based on four articles that reported the mortality risk (HR) of heart disease, with adjustment for gender, age at hire or year of birth, and smoking.

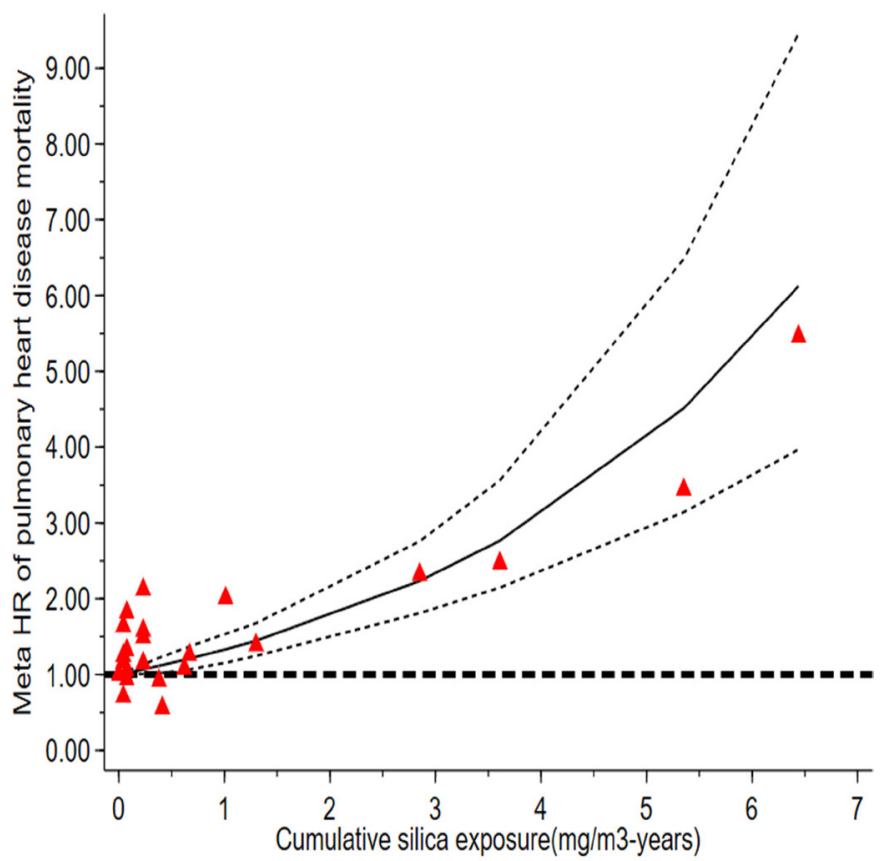

Figure 4 Exposure-response trend of pulmonary heart disease mortality with meta-HR (solid lines), $95 \% \mathrm{Cl}$ (short dashed lines) and yline=1 (thick dashed line).
Statistically significant evidence of linear association was found between occupational silica exposure and pulmonary heart disease ( $p$ of testparm doses results $=0.9627$; figure 4). The meta-risk estimate of pulmonary heart disease was 1.39 (95\% CI 1.19 to 1.62), while evidence of exposure-response analyses suggested a non-linear association between silica exposure and ischaemic heart disease ( $p$ of testparm doses results $=0.000$; figure 5 ). The metarisk estimate of ischaemic heart disease dropped to 0.98 , with no significance (95\% CI 0.91 to 1.05), compared with the overall heart disease risk estimate (meta-RR=1.08).

\section{DISCUSSION}

In this systematic review and meta-analysis, the association between occupational silica exposure and heart disease was investigated. Our results suggest that occupational silica exposure is associated with an increased risk of heart disease. Moreover, stronger evidence of positive associations with pulmonary heart disease was found in the risk estimate of both categories of heart disease and in the exposure-response analyses. In a meta-analysis of ischaemic heart disease studies, the risk of ischaemic heart disease was slightly increased, although not statistically significant. The positive association is consistent with previous studies. ${ }^{74223236}$ Our subgroup analyses also revealed that statistical heterogeneity was affected mainly by reference group, occupation and study quality score.

The diversity in the reference groups of the primary study might be a source of bias. ${ }^{22-27}$ Meta-analysis of studies with external control showed significantly increased risk for heart disease, but not for studies with total population control. This result might possibly be explained by 


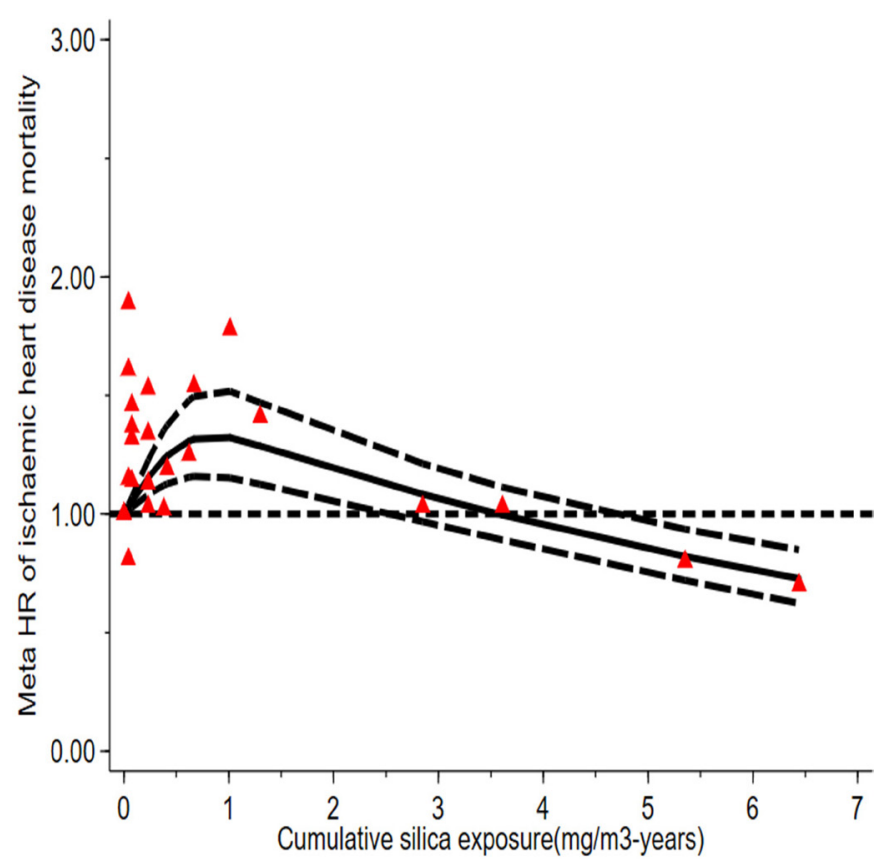

Figure 5 Exposure-response trend of ischaemic heart disease mortality with meta-HR (solid lines), $95 \% \mathrm{Cl}$ (long dashed lines) and yline $=1$ (thick dashed line).

healthy worker effect, which would normally cause bias towards the null. ${ }^{32}$

As for occupation, workplace changes related to silica forms may play an important role in affecting heart disease risk estimate. Our analysis of studies based on mine and stone foundry workers showed no significant increase in the risk of heart disease. However, Cherry et $a l^{20}$ revealed high standardised mortality ratio of all heart diseases among pottery and sandstone workers. Particulate matter size fractions and potential interaction of silica with ambient particulate should be considered. ${ }^{36-41}$

Other factors, in addition to silica, may have an impact on the risk for heart disease. Silica-exposed workers who have been smoking at least one cigarette per day for at least 6 months showed a significantly increased HR of ischaemic heart disease mortality. ${ }^{6}$ Moreover, study sample size, quality score, exposure measurement method, exposure assessment method, exposure types and research categories are important to estimate risk of heart disease.

Our exposure-response analyses revealed an excess risk of pulmonary heart disease in workers exposed to silica, but not for ischaemic heart disease. We acknowledge that substitution of open-ended lower category by the given bound divided by 1.2 might lead to overestimation of low-level exposure. However, the exact biological mechanisms underlying the non-significant dose-response association between occupational silica exposure and risk of ischaemic heart disease have not been fully understood. There is a higher likelihood that preceding respiratory disease is a competing cause of death for ischaemic heart disease. ${ }^{145}$ Chronic infectious respiratory tract disease also appears to play an independent role in the development of ischaemic heart disease. ${ }^{35} \mathrm{~A}$ case-control study showed that the impact of quartz dust on first acute myocardial infarction was observed only in a small subgroup that had virtually no pre-exposure to respirable quartz. ${ }^{42}$ This evidence might indicate a possible dynamic link among occupational silica exposure, respiratory disease, and ischaemic heart disease and stroke. ${ }^{13}$

The biological mechanisms by which occupational silica exposure could increase the risk of heart disease are not well understood. Coal dust may cause upregulation of leucocyte recruiting factors and damage of alpha-1-antitrypsin (A1AT), ${ }^{43}$ while relative elevations in leucocyte count and A1AT deficiency are associated with increased cardiovascular risk. ${ }^{44}$ Moreover, silica might induce inflammation, which plays a key role in coronary artery disease. ${ }^{464}$

\section{Strengths and limitations}

A major strength of the present study was the comprehensive and robust search strategy without any language restriction from all human cohort studies. A further strength was that we performed sensitivity analysis, subgroup analyses and exposure-response analyses. A major limitation was the high heterogeneity among studies, precluding to some degree firm conclusions. There were also few studies included in the exposureresponse analyses.

\section{CONCLUSION}

This review demonstrates that occupational silica exposure is associated with increased risk of heart disease, especially pulmonary heart disease. Confirmation of this positive association may have an important implication on primary prevention strategies for silica-related heart diseases.

\section{Author affiliations}

${ }^{1}$ Department of Biomarkers and Molecular Epidemiology, National Institute of Occupational Health and Poison Control, Chinese Center for Disease Control and Prevention, Beijing, China

${ }^{2}$ Department of Public Health, School of Medicine, Anhui University of Science and Technology, Huainan, Anhui, China

${ }^{3}$ Department of Nutritional Epidemiology, National Institute for Nutrition and Health, Chinese Center for Disease Control and Prevention, Beijing, China

${ }^{4}$ Department of Orthopaedics, Shanghai General Hospital, Shanghai Jiao Tong University School of Medicine, Shanghai, China

${ }^{5}$ Department of Occupational Epidemiology, National Institute of Occupational Health and Poison Control, Chinese Center for Disease Control and Prevention, Beijing, China

Acknowledgements We are sincerely grateful to the staff of the Chinese Center for Disease Control and Prevention, School of Medicine of the Anhui University of Science and Technology, and Orthopaedics of the Shanghai General Hospital, Shanghai Jiao Tong University School of Medicine. We also would like to add a word of thanks to Shu-zhen Han for her grammatical corrections and suggestions.

Contributors KL, MY, MM and WH conceived and designed this study. KL, MM, $\mathrm{KF}, \mathrm{YYQ}$ and $\mathrm{SX}$ searched the data. MY and WH performed the study inclusion and assessment of risk of bias. The manuscript was written by KL. All authors contributed to reviewing the study outcomes and approved the final version of the manuscript.

Funding This study was supported by grants from the National Natural Science Foundation of China $(81472956,30972449)$ and by the Occupational Health 
Risk Assessment and National Occupational Health Standard Setting Project (131031109000150003) of the National Institute of Occupational Health and Poison Control, Chinese Center for Disease Control and Prevention.

Competing interests None declared.

Patient consent for publication Not required.

Provenance and peer review Not commissioned; externally peer reviewed.

Data availability statement Data are available in a public, open access repository. Our raw data could be found in DRYAD, and the related final DOI number is 10.5061/dryad.5tb2rbp0x.

Open access This is an open access article distributed in accordance with the Creative Commons Attribution Non Commercial (CC BY-NC 4.0) license, which permits others to distribute, remix, adapt, build upon this work non-commercially, and license their derivative works on different terms, provided the original work is properly cited, appropriate credit is given, any changes made indicated, and the use is non-commercial. See: http://creativecommons.org/licenses/by-nc/4.0/.

ORCID iD

Kai Liu http://orcid.org/0000-0001-6452-9980

\section{REFERENCES}

1 Rocha-Parise M, Santos LMB, Damoiseaux JGMC, et al. Lymphocyte activation in silica-exposed workers. Int J Hyg Environ Health 2014;217:586-91.

2 Anlar HG, Bacanli M, İritaș S, et al. Effects of occupational silica exposure on oxidative stress and immune system parameters in ceramic workers in turkey. $J$ Toxicol Environ Health $A$ 2017;80:688-96.

3 Siribaddana AD, Wickramasekera K, Palipana WM, et al. A study on silicosis among employees of a silica processing factory in the central province of Sri Lanka. Ceylon Med J 2016;61:6-10.

4 Farazi A, Jabbariasl M. Silico-tuberculosis and associated risk factors in central province of Iran. Pan Afr Med J 2015;20:333.

5 Keil AP, Richardson DB, Westreich D, et al. Estimating the impact of changes to occupational standards for silica exposure on lung cancer mortality. Epidemiology 2018;29:658-65.

6 Lai H, Liu Y, Zhou M, et al. Combined effect of silica dust exposure and cigarette smoking on total and cause-specific mortality in iron miners: a cohort study. Environ Health 2018;17:46.

7 Steenland K, Sanderson W. Lung cancer among industrial sand workers exposed to crystalline silica. Am J Epidemiol 2001;153:695-703.

8 Vacek PM, Verma DK, Graham WG, et al. Mortality in Vermont granite workers and its association with silica exposure. Occup Environ Med 2011;68:312-8.

9 Dong D, Xu G, Sun Y, et al. Lung cancer among workers exposed to silica dust in Chinese refractory plants. Scand J Work Environ Health 1995;21:69-72.

10 Chen W, Liu Y, Wang $\mathrm{H}$, et al. Long-Term exposure to silica dust and risk of total and cause-specific mortality in Chinese workers: a cohort study. PLoS Med 2012;9:e1001206.

11 IARC Working group on the evaluation of carcinogenic risks to humans: silica, some Silicates, coal dust and Para-Aramid fibrils. Lyon, 15-22 October 1996. IARC Monogr Eval Carcinog Risks Hum 1997;68:1-475.

12 Occupational Safety and Health Administration (OSHA), Department of Labor. Occupational exposure to Respirable crystalline silica. final rule. Fed Regist 2016;81:16285-890.

13 Fan C, Graff P, Vihlborg P, et al. Silica exposure increases the risk of stroke but not myocardial infarction-A retrospective cohort study. PLoS One 2018;13:e192840.

14 Liu Y, Rong Y, Steenland K, et al. Long-Term exposure to crystalline silica and risk of heart disease mortality. Epidemiology 2014;25:689-96.

15 Lu Y, Zhang M. [Cohort study of ischemic heart disease among 1817 workers in a foundry]. Wei Sheng Yan Jiu 2012;41:824-30.

16 Weiner J, Barlow L, Sjögren B. Ischemic heart disease mortality among miners and other potentially silica-exposed workers. Am J Ind Med 2007;50:403-8.

17 Liu Y, Zhou Y, Hnizdo E, et al. Total and cause-specific mortality risk associated with low-level exposure to crystalline silica: a 44-year cohort study from China. Am J Epidemiol 2017;186:481-90.

18 Bjor B, Burstrom L, Eriksson K, et al. Mortality from myocardial infarction in relation to exposure to vibration and dust among a cohort of iron-ore miners in Sweden. Occup Environ Med 2010;67:154-8.

19 McDonald JC, McDonald AD, Hughes JM, et al. Mortality from lung and kidney disease in a cohort of North American industrial sand workers: an update. Ann Occup Hyg 2005;49:367-73.

20 Cherry NM, Burgess GL, Turner S, et al. Crystalline silica and risk of lung cancer in the potteries. Occup Environ Med 1998;55:779-85.

21 Reid PJ, Sluis-Cremer GK. Mortality of white South African gold miners. Occup Environ Med 1996;53:11-16.

22 Radican L, Blair A, Stewart P, et al. Mortality of aircraft maintenance workers exposed to trichloroethylene and other hydrocarbons and chemicals: extended follow-up. J Occup Environ Med 2008;50:1306-19.

23 Graham WGB, Costello J, Vacek PM. Vermont granite mortality study: an update with an emphasis on lung cancer. J Occup Environ Med 2004;46:459-66.

24 Miller BG, MacCalman L. Cause-Specific mortality in British coal workers and exposure to respirable dust and quartz. Occup Environ Med 2010;67:270-6.

25 Checkoway H, Heyer NJ, Seixas NS, et al. Dose-Response associations of silica with nonmalignant respiratory disease and lung cancer mortality in the diatomaceous earth industry. Am J Epidemiol 1997;145:680-8.

26 Cherry N, Harris J, McDonald C, et al. Mortality in a cohort of Staffordshire pottery workers: follow-up to December 2008. Occup Environ Med 2013;70:149-55.

27 Zhang X, Wang H, Zhu X, et al. Cohort mortality study in three ceramic factories in Jingdezhen in China. J Huazhong Univ Sci Technolog Med Sci 2008;28:386-90.

28 Sjogren B. Occupational exposure to dust: inflammation and ischaemic heart disease. Occup Environ Med 1997;54:466-9.

29 Moher D, Liberati A, Tetzlaff J, et al. Preferred reporting items for systematic reviews and meta-analyses: the PRISMA statement. BMJ 2009;339:b2535.

30 Ofek Shlomai N, Rao S, Patole S. Efficacy of interventions to improve hand hygiene compliance in neonatal units: a systematic review and meta-analysis. Eur J Clin Microbiol Infect Dis 2015;34:887-97.

31 Greenland S. Quantitative methods in the review of epidemiologic LITERATURE1. Epidemiol Rev 1987;9:1-30.

32 Melsen WG, Bootsma MCJ, Rovers MM, et al. The effects of clinical and statistical heterogeneity on the predictive values of results from meta-analyses. Clin Microbiol Infect 2014;20:123-9.

33 Palmer TM, Sterne JAC. Meta-Analysis: an updated collection from the Stata Journal. Crc Press, 2009.

34 Longnecker MP, Berlin JA, Orza MJ, et al. A meta-analysis of alcohol consumption in relation to risk of breast cancer. JAMA 1988;260:652-6.

35 Koskela R-Set al. Respiratory disease and cardiovascular morbidity. Occup Environ Med 2005;62:650-5

36 Fang SC, Cassidy A, Christiani DC. A systematic review of occupational exposure to particulate matter and cardiovascular disease. Int J Environ Res Public Health 2010;7:1773-806.

37 Park E-K, Thomas PS, Wilson D, et al. Chest pain in asbestos and silica-exposed workers. Occup Med 2011;61:178-83.

38 Kumagai N, Nishimura Y, Maeda M, et al. Immunological effects of Silica/Asbestos. Jpn. J. Hyg. 2010;65:493-9.

39 Msiska Z, Pacurari M, Mishra A, et al. Dna double-strand breaks by asbestos, silica, and titanium dioxide: possible biomarker of carcinogenic potential? Am J Respir Cell Mol Biol 2010;43:210-9.

40 Matsuzaki H, Kumagai-Takei N, Lee S, et al. Search for biomarkers of asbestos exposure and asbestos-induced cancers in investigations of the immunological effects of asbestos. Environ Health Prev Med 2017;22:53.

41 Maeda M, Nishimura Y, Kumagai N, et al. Dysregulation of the immune system caused by silica and asbestos. J Immunotoxicol 2010;7:268-78.

42 Gellissen J, Pattloch D, Möhner M. Effects of occupational exposure to respirable quartz dust on acute myocardial infarction. Occup Environ Med 2019;76:370-5.

43 Schins R, Borm PJ. Mechanisms and mediators in coal dust InducedToxicity: a review. Ann Occup Hyg 1999;43:7-33.

44 Elkind MSV, Sciacca RR, Boden-Albala B, et al. Relative elevation in baseline leukocyte count predicts first cerebral infarction. Neurology 2005;64:2121-5

45 Curjuric I, Imboden M, Bettschart R, et al. Alpha-1 antitrypsin deficiency: from the lung to the heart? Atherosclerosis 2018:270:166-72.

46 Adelroth Eet al. Airway inflammation in iron ore miners exposed to dust and diesel exhaust. Eur Respir J 2006;27:714-9.

47 Hansson GK. Inflammation, atherosclerosis, and coronary artery disease. N Engl J Med 2005;352:1685-95. 